\title{
Modulation of Metabolic Changes Associated to Obesity and Aging using a Grape Seed Proabthocyabidin Extract
}

\author{
Raúl Beltrán-Debón * \\ MoBioFood Research Group, Departament de Bioquímica i Biotecnologia, Universitat Rovira i Virgili, \\ c/Marcel-lí Domingo n 1, 43007 Tarragona, Spain \\ * Correspondence: raul.beltran@urv.cat
}

Published: 30 October 2020

\begin{abstract}
Obesity is a worldwide problem. In addition to this disorder, we have to include in the equation the fact that the population is also getting older. For that reason, we must study obesity also in aged models. In our group, we are used to studying the effects of food and food components on health in different situations. Particularly, we have experience with a grape seed proanthocyanidin extract (GSPE). This extract rich in proanthocyanidins prevent body weight gain, hyperlipidemia and liver fat deposition in animal models of obesity. For that reason, we aimed to explore the GSPE effects in the same animal model but adding the variable of age. In this presentation, I show preliminary results of that experiment. 21 months old rats were fed with cafeteria diet. We assayed 2 ways of administration: the pre-treatment with GSPE before the cafeteria diet onset, and the simultaneous administration of hypercaloric diet and GSPE during the study. GSPE prevented body weight gain in both groups, being more significant the results obtained in the synchronic group. The same situation occurred with total adiposity. Finally, GSPE prevented the accumulation of ectopic lipids in the liver in the simultaneous treatment group.
\end{abstract}

Publisher's Note: MDPI stays neutral with regard to jurisdictional claims in published maps and institutional affiliations.

(C) 2020 by the authors. Submitted for possible open access publication under the terms and conditions of the Creative Commons Attribution (CC BY) license (http://creativecommons.org/licenses/by/4.0/). 